\title{
Semiconductor optical amplifiers: performance and applications in optical packet switching [Invited]
}

\author{
Ian Armstrong and Ivan Andonovic \\ Department of Electronic and Electrical Engineering Royal College, University of Strathclyde, \\ 204 George Street, Glasgow G1 1XW, UK \\ Anthony E. Kelly \\ Department of Electronics and Electrical Engineering, Rankine Building, University of \\ Glasgow, Oakfield Avenue, Glasgow G12 8LT, UK \\ iarmstrong@eee.strath.ac.uk \\ tkelly@elec.gla.ac.uk
}

RECEIVED 2 AUGUST 2004; REVISED 8 SEPTEMBER 2004;

ACCEPTED 20 OCTOBER 2004; PUBLISHED 00 NOVEMBER 2004

\begin{abstract}
Semiconductor optical amplifiers (SOAs) are a versatile core technology and the basis for the implementation of a number of key functionalities central to the evolution of highly wavelength-agile all-optical networks. We present an overview of the state of the art of SOAs and summarize a range of applications such as power boosters, preamplifiers, optical linear (gain-clamped) amplifiers, optical gates, and modules based on the hybrid integration of SOAs to yield high-level functionalities such as all-optical wavelength converters/regenerators and small space switching matrices. Their use in a number of proposed optical packet switching situations will also be highlighted. (C) 2004 Optical Society of America

OCIS codes: $060.4510,130.3120,250.5980$.
\end{abstract}

\section{Introduction}

One route to meeting the growing demand for network capacity is the all-optical network supporting packet transmission and routing [1]. A number of systems have been demonstrated [2-4] that require a range of functionalities such as gating, routing, power equalization, wavelength conversion, and all-optical regeneration. The semiconductor optical amplifier (SOA) is a versatile candidate technology for executing such operations. This paper reviews recent developments in SOA technology and describes the current state of the art with respect to performance. A number of traditional SOA applications are summarized and, in particular, their role in the implementation of new optical routing nodes supporting packet transmission and switching is highlighted.

\section{SOA Improvements}

Recent developments in SOA technology and the resultant improvements in performance are due to a combination of design and technology.

\section{A. Control of Optical Mode Profile}

The modal profile at the facet of the device is of critical importance, since it will determine not only the coupling efficiency to optical fiber and other optical components but also the effective facet reflectivity when angled facets are used. Coupling efficiency of a SOA into fiber affects the module's optical performance; poor input coupling increases the module noise figure (NF); poor output coupling degrades the output saturation power of the module; while both input and output coupling are detrimental to the fiber-to-fiber gain of a device. In early SOA designs the waveguide was little changed from that of a semiconductor laser, which resulted in a very divergent output mode and consequent low coupling to fiber [Fig. 1(a)]. The use of lateral [5-7] or vertical [8] tapering of the active region allows a different confinement factor in the middle of the device while maintaining an optimum output mode. In some designs the active waveguide taper is augmented by 
an underlying passive waveguide to expand the mode further $[5,9,10]$. For dilute mode designs $[11$, 12], the waveguide is invariant along the length of the SOA and typically consists of a wide ( $\sim 3$ $\mu \mathrm{m})$, thin $(\sim 0.05 \mu \mathrm{m})$ active layer. Coupling to lensed optical fiber can be achieved with losses of less than $1 \mathrm{~dB}$ per facet by careful matching of the optical mode in the fiber and the device [Figs. $1(b)$ and $1(\mathrm{c})]$ providing benefits with respect to reduced NF values.

a)

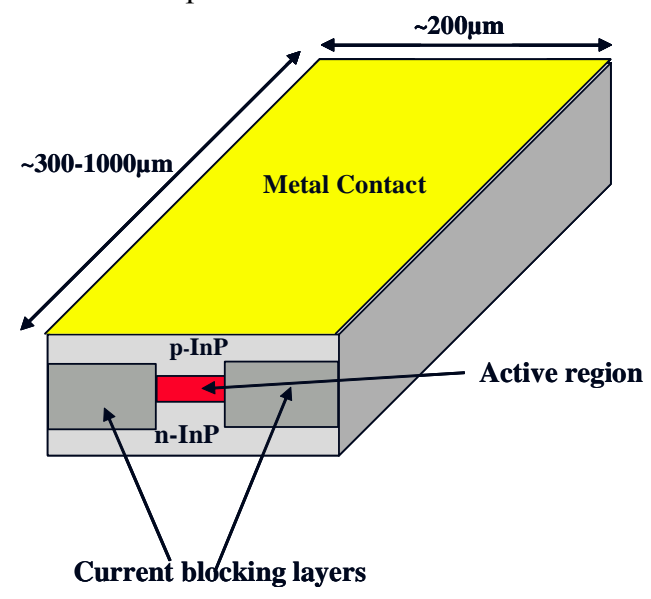

b)

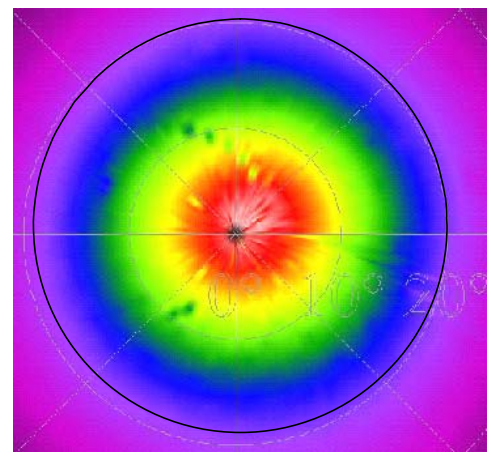

c)

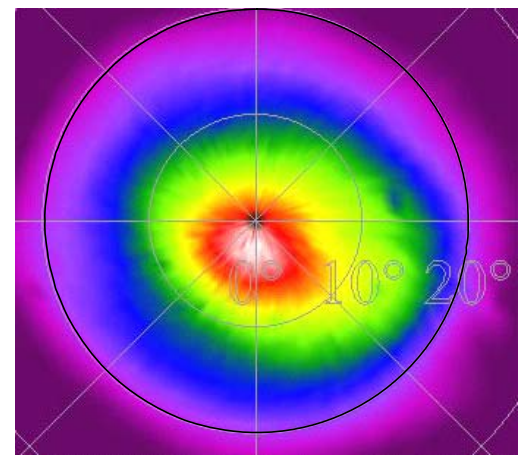

Fig. 1. (a) Schematic of an SOA. Farfield profiles for a (b) SOA device and a (c) lensed fiber suitable for low-loss coupling. The black circle is a far field angle of $20 \mathrm{deg}$, and the interface between green and yellow is the $3-\mathrm{dB}$ point relative to peak intensity.

\section{B. Increased Output Power}

In certain applications (e.g., as a power booster) the SOA output power is a key parameter. Using wide, dilute waveguides $[6,11,12]$, where the SOA has a low confinement factor and therefore a low photon density, has resulted in saturated output powers of around $+17 \mathrm{dBm}$; with quantum dot active regions the power can be increased to $+23 \mathrm{dBm}$ [13]. The main drawbacks of this approach are the increased length and drive current requirements, e.g., for the above SOA a current drive of 2.5 A with a device length of $6.15 \mathrm{~mm}$ was required.

\section{C. Low Polarization Dependence}

Ideally the polarization-dependent gain of SOAs should be negligible. Generally the preferred means for reducing the polarization dependence requires the introduction of a tensile strain in a bulk active region $[5-7,11]$. The TE waveguide mode has a higher confinement factor than the TM mode, but tensile strain makes the TM material gain higher than that of TE. It is therefore possible to balance the two influences leading to polarization independence. Excessive strain levels, however, lead to a wavelength difference between the TE and TM gain peaks, which ultimately limits the scale of the confinement factor ratio that can be compensated. One of the key benefits of this approach to achieving polarization insensitivity is that the confinement factor ratio is substantially constant with waveguide width in most designs [14], which means that such a design is robust to variations in lithography [12]. With high-quality epitaxial growth, SOAs of this type routinely exhibit less than 1- 
$\mathrm{dB}$ polarization dependence across a $50-\mathrm{nm}$ bandwidth. If strain is not used for controlling polarization dependence, it is possible to fabricate SOAs where the waveguide is symmetric with dimensions of approximately $0.4 \mu \mathrm{m}$ [15], although this type of design is more susceptible to variances in mesa width. Quantum-well active regions can also be used [9, 16-18] resulting in performance that is broadly similar to that of their bulk counterparts - the main advantage being the possibility of broader gain bandwidth at the expense of more complicated epitaxial growth.

\section{D. Integration with Waveguides}

The use of on-chip, mode expanders enables the hybrid integration of SOAs or SOA arrays with passive waveguides leading to small form factor devices with high levels of functionality. This can also be achieved by the monolithic integration of passive waveguides either by postgrowth processing [19] or by low pressure or selective regrowth technologies [20]. In addition to linear amplification, a SOA can be used as a high-speed, high-extinction-ratio gate and a nonlinear waveguide for all-optical switching. This allows a variety of functions to be realized with this technology such as wavelength selectors [21, 22], broadcast-and-select space switches [23], and alloptical gates such as wavelength converters and regenerators [24-26].

\section{E. Optimization for All-Optical Switching}

In SOA-based optical signal processing, two (or more) signals are launched into the SOA where they interact in response to the nonlinear properties of the active region in gain saturation, allowing the amplitude and phase of one optical signal to be controlled by another optical signal. Depending on the input conditions and topology, this can result in cross-gain modulation (XGM), cross-phase modulation (XPM), or four-wave mixing (FWM). This situation is very different than with the traditional role of SOAs as linear amplifiers, and the optimum device structure is very different as well. The main differences are in length, where increasing the length leads to an improvement in alloptical modulation bandwidth [27] FWM efficiency [28], and choice of material bandgap, where a band edge close to the operating wavelength leads to improved switching performance [29] and lower gain dispersion when the device is heavily saturated [30].

\section{F. Gain Clamping}

Gain clamping is used to lock the carrier density to a particular level within the device by creation of a controlled lasing mode outside the wavelength of operation, achieved by integrated distributedfeedback (DFB) or distributed Bragg reflector (DBR) reflectors, external gratings, or by vertical cavity lasing [31]. The saturation output power of the device is therefore increased (Fig. 2) because of the "reservoir" effect introduced by the lasing mode at the expense of a reduction in available gain. The saturation output power of the amplifier is increased, exhibiting a much steeper roll off into saturation as the lasing mode loses power and eventually collapses. Multichannel systems experiments [32] have shown the suitability of such devices for operation in a WDM environment [33]. The performance advantage of gain-clamped devices over a SOA designed to have a similarly low value of gain is complicated, however, since the dynamic behavior does not follow the dc characteristics. One clear performance advantage of gain-clamped devices over their non-clamped counterparts is the ability to choose the gain clamping point via the magnitude and position in wavelength of the reflection such that the gain flatness is greatly increased. This is shown in Fig. 2 where the gain variation over the C-band can be seen to be reduced when the device is gain clamped. Since the carrier density is reduced compared with a non-clamped device, the NF is generally higher. 

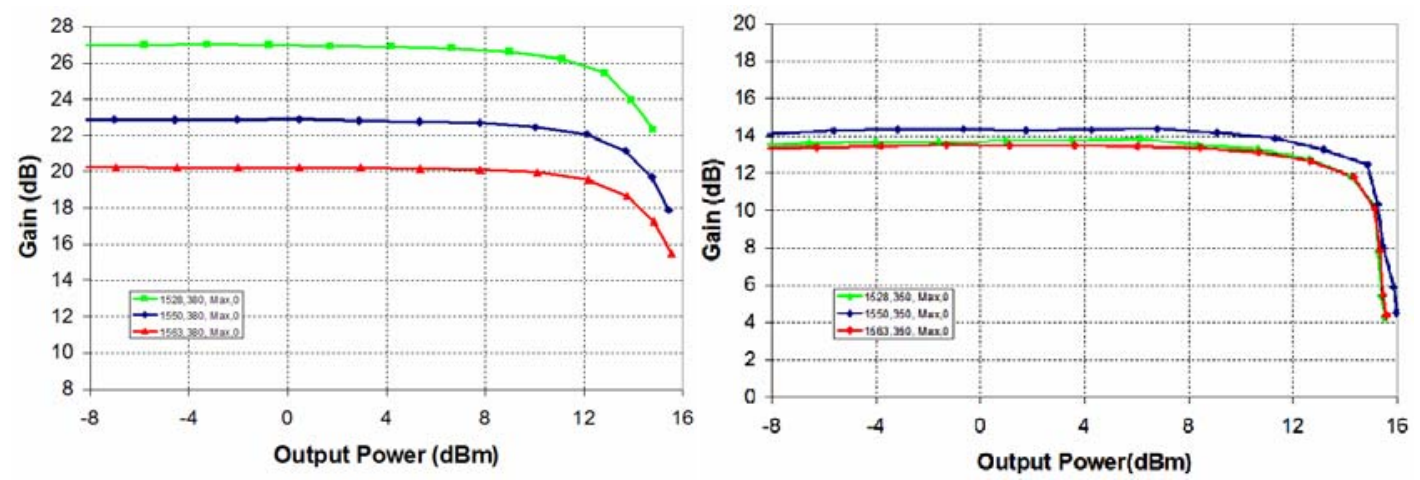

Fig. 2. Gain versus output power for unclamped (LHS) and clamped SOA operation.

These improvements have led to devices with greatly improved characteristics. Figure 3 shows typical performance for a modern SOA optimized for high-gain linear applications such as preamplification. NFs of _ $6 \mathrm{~dB}$ can routinely be achieved with values less than $5 \mathrm{~dB}$ possible [7], and saturation output powers of up to $17 \mathrm{dBm}$ for polarization independent devices have been achieved. Table 1 summarizes recent reports of high performance polarization-independent SOAs.

\section{Traditional SOA Applications}

In addition to SOA applications specific to packet switching, there are "traditional" applications which exist both in packet switching and point to point links.

\section{A. Power Booster}

Systems using relatively inexpensive, low-power or latterly tunable lasers may need the signal power to be increased at the launch to the link. A power booster SOA variant is one route to providing this amplification. Booster characteristics typically include relatively low-gain (_10-15 dB), high-output saturation powers in order to create the required input signal launch conditions.

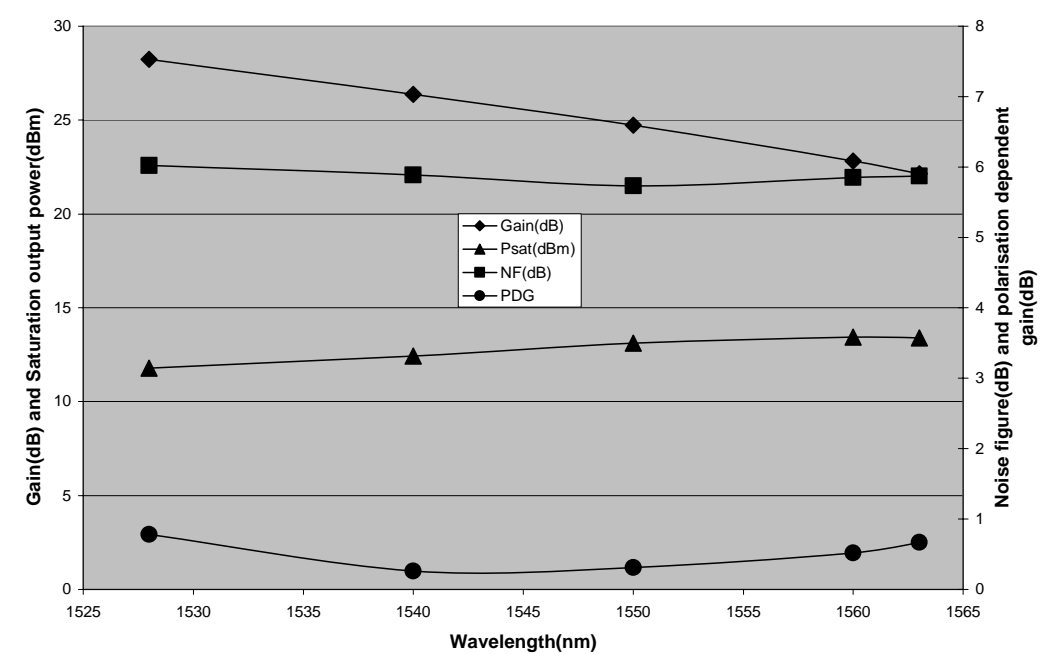

Fig. 3. Example of a high-performance SOA, in this case a high-gain preamplifier device. 
Table 1. Summary of Recent SOA Results

\begin{tabular}{|c|c|c|c|c|c|}
\hline \multicolumn{3}{|c|}{ Active region details } & \multicolumn{3}{|c|}{ Coupling } \\
\hline width(um) & thickness & material & Mode adaption & Method & loss(dB) \\
\hline 1.4 & 50nm with 100nm Q1.2 SCH & Bulk & lateral taper & lens + isolator & 2 \\
\hline 3 & 50nm with Q1.3 SCH & MQW & none & 10um lensed fibre & 1 \\
\hline 3 & 50nm with 20nm Q1.3 SCH & Bulk & none & 9um lensed fibre & 1.3 \\
\hline 1.4 & 100nm with Q1.1 SCH & Bulk & lateral taper & 10 um lensed fibre & 1 \\
\hline & Ch & acteristic & & & \\
\hline$N F(d B)$ & Gain(dB) & Psat(dBm) & length(mm) & $\mathrm{I}(\mathrm{mA})$ & Ref \\
\hline 7 & 19 & 17 & 0.9 & 500 & [34] \\
\hline 5.7 & 15 & 16.5 & 1.6 & 500 & [12] \\
\hline 7 & 27 & 17 & 3 & 1500 & [11] \\
\hline 5.7 & 27 & 14.7 & 1 & 450 & [7] \\
\hline
\end{tabular}

Noise figure in this application is of less concern, but it is, as always, preferable to keep it as low as possible. Gain-clamped devices lend themselves to this application, since low gains are typically required and gain flatness is important. However, the ability to vary the gain to balance the power from different sources would be advantageous, and in the case of tunable lasers, the gating (off state) property of the SOA will obviate the problems associated with the transition between wavelengths. Varying the gain with a gain-clamped SOA is not possible and is certainly not advisable in a standard SOA, since reducing the gain results in a reduction in output power that leads to device saturation (Fig. 9 below). This causes patterning and additional chirp on the signal. Ideally a gainclamped SOA with variable gain would be used.

\section{B. Pre-amplifier}

To increase receiver sensitivity, optical amplification can be used directly in front of a detector. The dominant noise process in the receiver now moves from thermal to signal-spontaneous beat noise, and although the power at the detector required to achieve a given bit error rate (BER) is increased, the power required at the SOA input is reduced compared with that of a PIN detector alone. With regard to the SOA design, it is important that sufficient gain be provided such that the dominant noise process becomes signal-spontaneous beat noise, and beyond this point improvements can be made only by decreasing the NF. Figure 4 shows the calculated receiver sensitivity versus gain at $10-$ and $40-$ Gbit/s data rates.

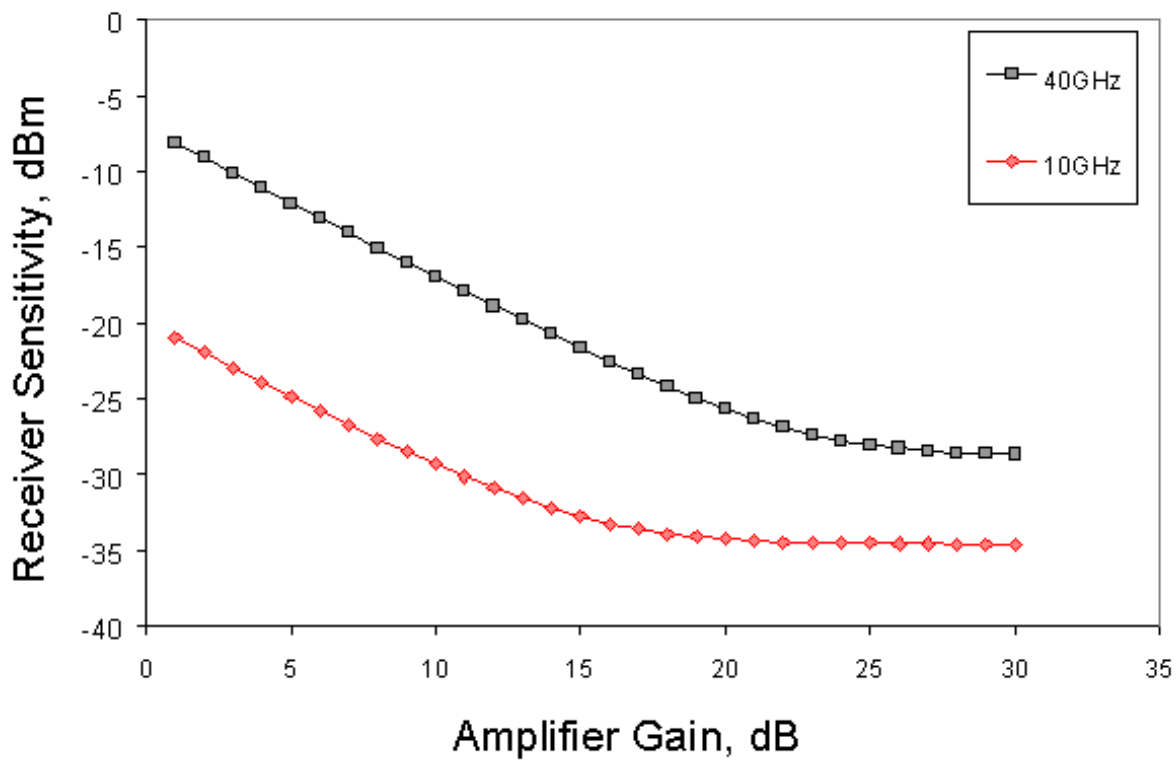

Fig. 4. Receiver sensitivity versus optical preamplifier gain.

The sensitivity is largely unchanged for gains $>20 \mathrm{~dB}$ at $10 \mathrm{Gbit} / \mathrm{s}$ with the optimum gain for 40 Gbit/s being slightly higher owing to the larger thermal noise element. Figure 5 shows measurements 
of the sensitivity enhancement for a SOA with 6.5-dB NF at $10 \mathrm{Gbit} / \mathrm{s}$. An enhancement of $12 \mathrm{~dB}$ is available with a bandpass filter and $8 \mathrm{~dB}$ when no filtering is used; similar performance benefits are available at $40 \mathrm{Gbit} / \mathrm{s}$.

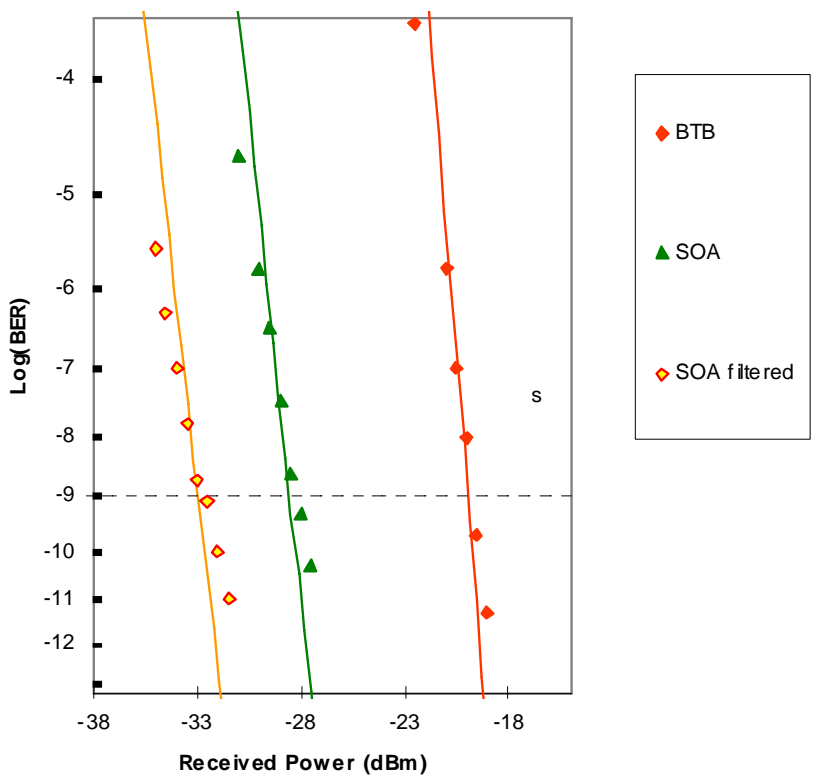

Fig. 5. PIN, unfiltered preamp and filtered preamp BER performance at $10 \mathrm{Gbit} / \mathrm{s}$. A SOA preamplified receiver has a number of other advantageous characteristics.

(1) Since the receiver is operating in the signal-spontaneous noise limit, these values of sensitivity enhancement can still be achieved with significant amounts of loss between the SOA and the PIN detector, since both noise and signal are being attenuated. This allows functions such as demultiplexing to be implemented with no reduction in sensitivity.

(2) The SOA can amplify multiple channels at the same time, since the output power per channel is modest for most systems. The maximum number of channels depends on channel spacing and the amount of power required at the detector for each channel. Eight WDM channels at 50-GHz spacing can be amplified with no reduction in sensitivity compared with the single-channel case.

(3) $\mathrm{A}>40 \mathrm{~dB}(-32$ to $+10 \mathrm{dBm})$ input power dynamic range can be achieved by keeping the power at the detector constant at around $-5 \mathrm{dBm}$ via direct control of the SOA gain in tandem with a limiting electronic amplifier after the PIN detector. Although this leads to the SOA operating in saturation at certain input powers, patterning is reduced by the limiting amplifier and additional chirp is not problematic, since there is no onward transmission.

(4) The SOA can be co-packaged with the PIN detector and filter. Because of point (1) above, the coupling between the SOA and the PIN detector is not of critical importance.

\section{Packet Switching Requirements}

All-optical packet switches have been the subject of significant research worldwide. The extent of the implementation, reflected by the complexity of the optical layer, will determine the functionality required of the node. In simple terms the optical node - in its most complex realization emulating the functions of an electronic packet switch-needs to switch and buffer all-optical "containers" (an optical packet containing one or more electronic packets). The resultant architectures can be realized with or without optical-electronic interfaces. In the former case the $\mathrm{O} / \mathrm{E}$ and $\mathrm{E} / \mathrm{O}$ interfaces [35] can adopt the SOA - ideally in an integrated platform - as a power booster and/or preamplifier dependent on the power budget limitation of what are highly lossy geometries. However, in order to illustrate some of the other functions relevant to all-optical packet node implementations, two examples, representing more-aggressive solutions, are discussed in summary.

\section{A. KEOPS}


The KEys to Optical Packet Switching (KEOPS) project proposed and demonstrated the broadcastand-select all-optical packet switch (Fig. 6). It is fair to observe that this switch was one of the first architectures that embodied the required functionalities needed to understand the difficulties and test all-optical packet routing and buffering concepts. As such, the byproduct of the project was the development of key device/component modules that supported this aggressive architecture. Inputs are fed through tunable wavelength converters to select their desired output wavelength before they are multiplexed and split between various optical fiber delay lines (FDLs). Control electronics governing optical gates in the next stage of the switch can then select the most suitable delay line and filter off unwanted signals after a demultiplexer, before the new WDM signals are sent out the correct port. This concept used FDLs as the core contention-resolution mechanism (the chosen wavelength and gate selecting the appropriate FDLs) and therefore is limited in the depth of the buffer that can be practically realized.

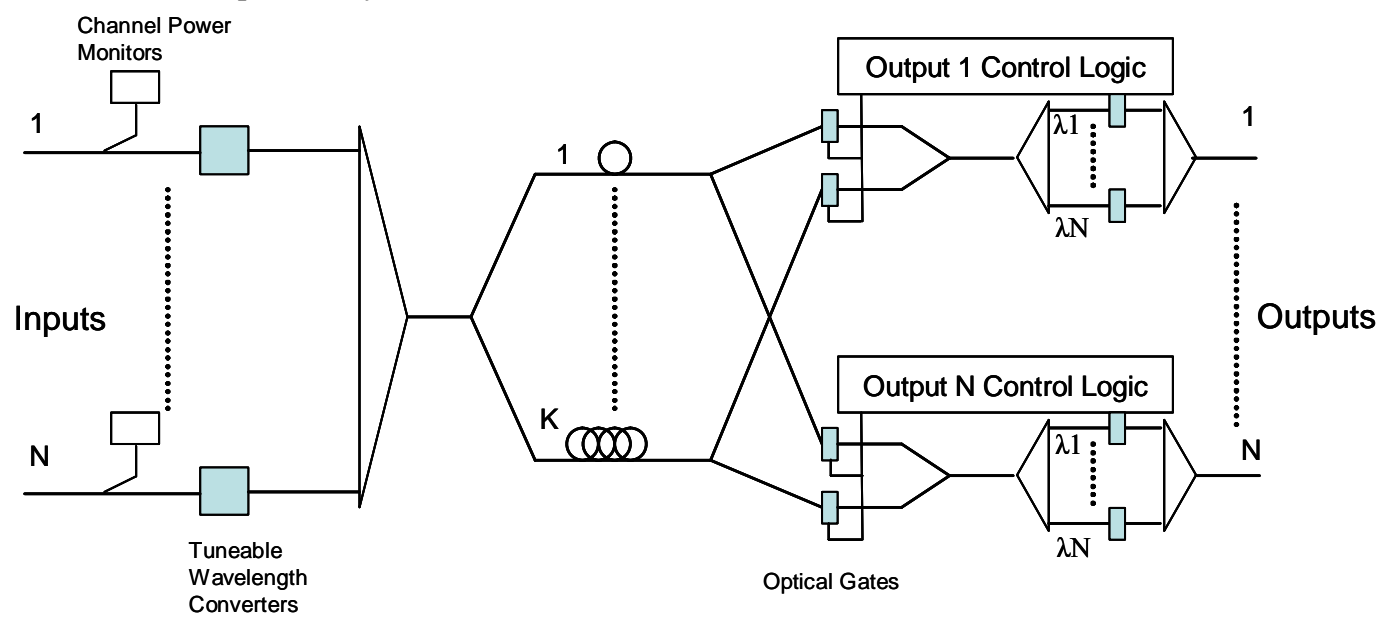

Fig. 6. KEOPS all-optical packet switch [36].

This architecture uses SOAs to provide three key functionalities: the tunable wavelength converters used to move signals onto output carrier wavelengths (Section 5), later sections of the switch use the SOA as an ON-OFF gate in a broadcast-and-select switch, and SOAs are also used for fast power equalization. Equalisation is required because of the different passive losses encountered for different FDL lengths and also the wavelength dependence of the output power of the wavelength converters. This power equalization has to occur on a packet-by-packet basis precluding thermooptic or EDFA-based gain equalization schemes (EDFA, erbium-doped fiber amplifier). The architecture has been demonstrated in a $16 \times 16$ switch realization [36], where it has shown low power penalties of $<2 \mathrm{~dB}$ for a BER of $10^{-9}$ at rates up to $10 \mathrm{Gbit} / \mathrm{s}$.

\section{B. WASPNET}

The Wavelength Switched Packet NETwork (WASPNET) in comparison is based around fixed routing, arrayed waveguide gratings (AWGs) [37] (Fig. 7). To provide the dynamic routing aspect to the switch, tunable wavelength converters are used to select the AWG port that a signal will exit from. The initial converter-AWG pairing selects the intermediate branch in the switch through which the signal will be routed. During propagation through this branch, the signal is split through several delay lines of which only one is selected by optical gates to ensure the packet is suitably routed to the output during a free time slot. The delayed signal undergoes a second shift that places it on its desired output carrier wavelength and is routed through the output AWG to the correct port. Control electronics must therefore use a lookup table in order to convert the incoming signal to the correct intermediate wavelength so that the second shift-and-route section places the signal onto the correct output port. Thus packet contention occurs through the combination of wavelength and physical delay lines. In so doing the bulk of the burden is removed from the FDLs, promoting a more practical route to buffering and allowing relatively deep buffers to be implemented.

As with the KEOPS node, this architecture uses SOAs in the gating and wavelength conversion processes, with electronics to control the redirection and buffering of packets. These components can therefore be integrated directly into the design of the switch, the technologies being highly 
compatible. In addition to these functions within packet switches, SOAs are likely to be deployed within many optical nodes to manage the required path power budgets while preserving transparent operation.

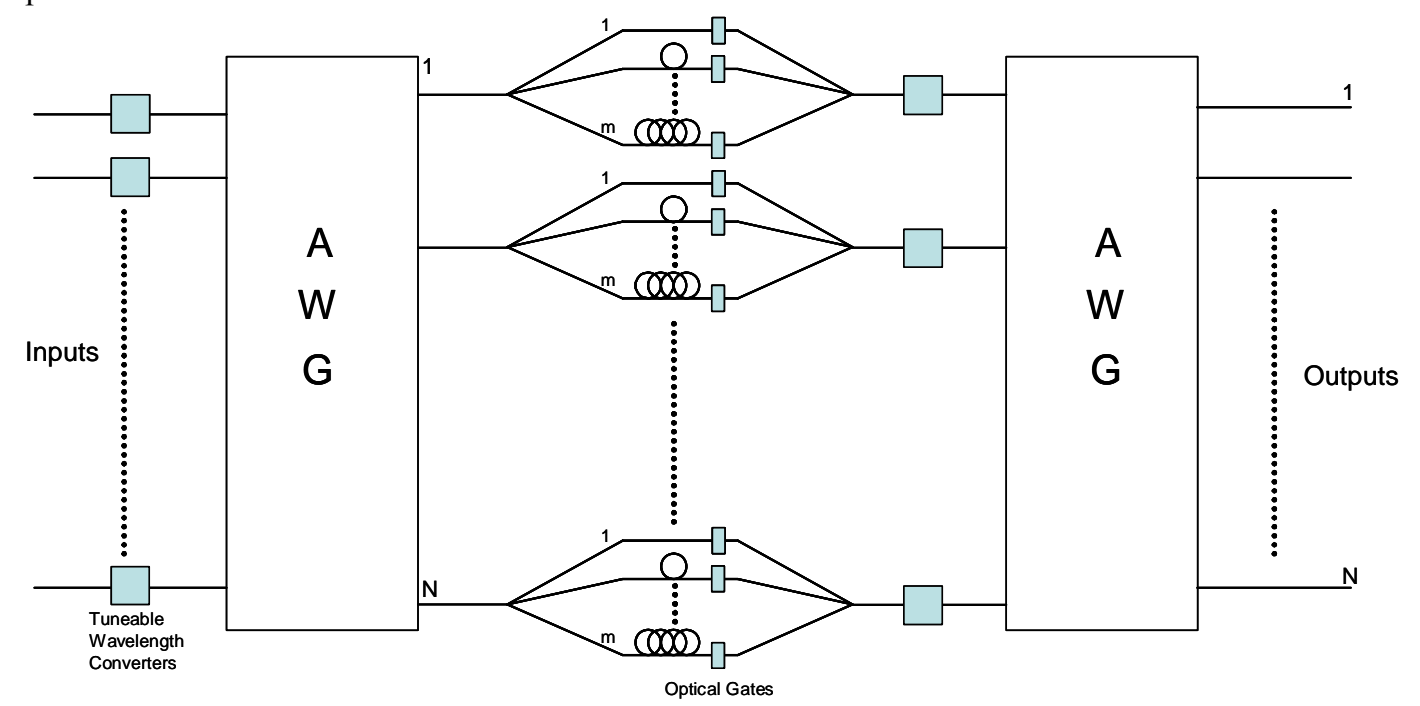

Fig. 7. WASPNET feed-forward all-optical packet switch [37].

Demonstration of the WASPNET architecture at $2.5 \mathrm{Gbit} / \mathrm{s}$ has shown that the scheme can be cascaded to include fourteen $4 \times 4$ switches (implemented using a circulating loop) resulting in a small penalty of $1 \mathrm{~dB}$ for a BER of $10^{-9}$.

\section{SOA Applications in Packet Switching}

\section{A. High-Speed Gating}

Direct electronic drive permits the realization of switching functionalities [38]. The incorporation of a gain block into a switching fabric performs two functions: first, it can be biased to counteract the losses imposed on the signals within the switch block while implementing channel power equalization, the data being routed transparently and without reduction of signal strength. Second, using broadcast-and-select architectures and using the SOA as a gate, the SOA can be used as the means by which the signals are routed. An unbiased SOA becomes heavily absorbing and consequently blocks any signal attempting to pass through it with ON-OFF ratios of $>60 \mathrm{~dB}$. Furthermore, the fast nature of such a gating process [39] would allow for a network to route data on a packet-by-packet basis [40].

\section{B. All-Optical Wavelength Converters}

All-optical wavelength converters (AOWCs) provide core functionality in a flexible all-optical network infrastructure. The inability to switch data streams between optical carriers limits both the connection path capability (through wavelength) as well as increasing the probability of port blocking, and therefore information loss [41]. The latter is also important in creating a viable and practical solution to resolve contention in packet-switched networks (see Section 4). Development of AOWCs enables this functionality without the need to transfer the data back into the electrical domain before they are relaunched on the desired wavelength, avoiding any electrical processing bottlenecks.

The use of SOAs within these modules harnesses three major conversion mechanisms.

(1) Cross-gain modulation (XGM) uses the saturable gain properties of the SOA to imprint an inverted version of the original data onto a CW signal [42]. The advantage of XGM is its stability and robust nature, and it has been used as an input stage for a packet node [43].

(2) Cross-phase modulation (XPM) places SOAs in an interferometer configuration (Fig. 8) and uses the phase modulation that accompanies the gain saturation to modulate a local $\mathrm{CW}$ signal. Practical XPM devices require integration of SOAs with passive waveguides [24, 44], since fiber-based schemes have poor stability. 
(3) The third major conversion mechanism is based on four-wave mixing [45], although this scheme is more commonly used for demultiplexing [46] or packet header recognition [47]. These types of wavelength conversion schemes have shown successful operation up to at least $80 \mathrm{Gbit} / \mathrm{s}$ [48, 49].

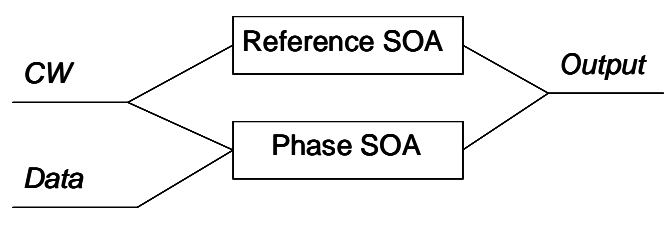

a

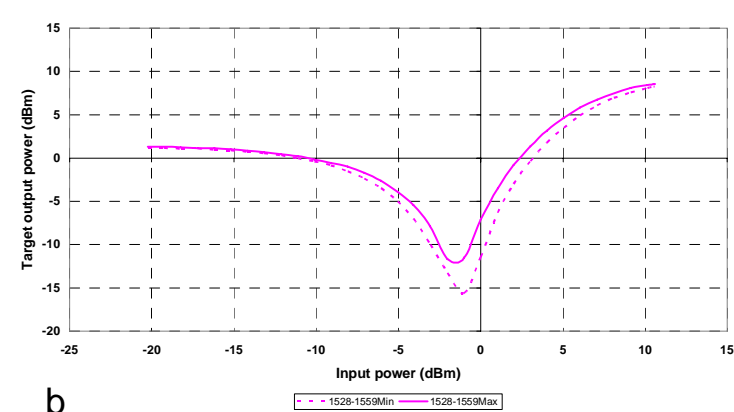

Fig. 8. Hybridized XPM AOWC (a) copropagating MZI schematic (b) transfer function [45].

\section{C. Regeneration}

Optical regeneration capabilities are required for long-haul links currently, but with reduction in electrical processing points within networks, data traversing several nodes will need to be alloptically regenerated in some form in order to maintain the advantageous features of all-optical networking, especially at rates beyond $10 \mathrm{Gbit} / \mathrm{s}$. XPM wavelength converters have a nonlinear transfer characteristic that allows regeneration of signals directly in the optical domain, and operating in this mode has been shown to be infinitely cascadable [50].

\section{D. Optical Logic}

Optical processing abilities [51] are required for a variety of purposes in a flexible optical layer, with the SOA being used in number of applications. Realization of optical half $[52,53]$ and full [54] adders, incorporating AND, OR, and XOR functions have been shown and can be seen to have packetheader recognition applications. Header extraction and processing techniques have been able to make use of the SOA's birefringence to manipulate signal polarization states in order to facilitate the required optical logic functions [55, 56]. Similar polarization effects have been presented at optical rates of $>100 \mathrm{Gbit} / \mathrm{s}$ in an all-optical routing system [57] using AND logic for 4-bit address recognition. Work has also been presented on the realization of an all-optical flip-flop in which lasing is induced in one or other of two SOAs to signify the SET or RESET states [58]. Additional optical functionalities such as parity checking [59], pseudorandom number generation [60], and clock division $[61,62]$ have all been realized using all-optical gates based on SOAs.

A main weakness for all-optical logic is the nonexistence of optical random access memory (RAM), which means that serial optical memories have to be used, resulting in large latencies in access times. This is particularly problematic for packet switching where buffering is a key functionality. Packet contention resolution is therefore commonly implemented using physical delay lines as shown in the previous examples. Nevertheless, the demonstration of a full 10-Gbit/s memory, where a $2^{7}-1$ packet was stored for tens of thousands of circulations, has been achieved using a single SOA gate [63].

\section{E. High-Speed Power Equalization and Control}

Direct current control of a SOA can be used to implement high-speed power equalization [64], although this scheme has the drawback that the saturation output power of the SOA will also vary while the gain is being varied, which means that automatic power control (APC) schemes can be implemented only at low output powers. Figure 9 shows the saturation characteristic of a SOA at bias currents from 50 to $300 \mathrm{~mA}$ in $50-\mathrm{mA}$ steps. 


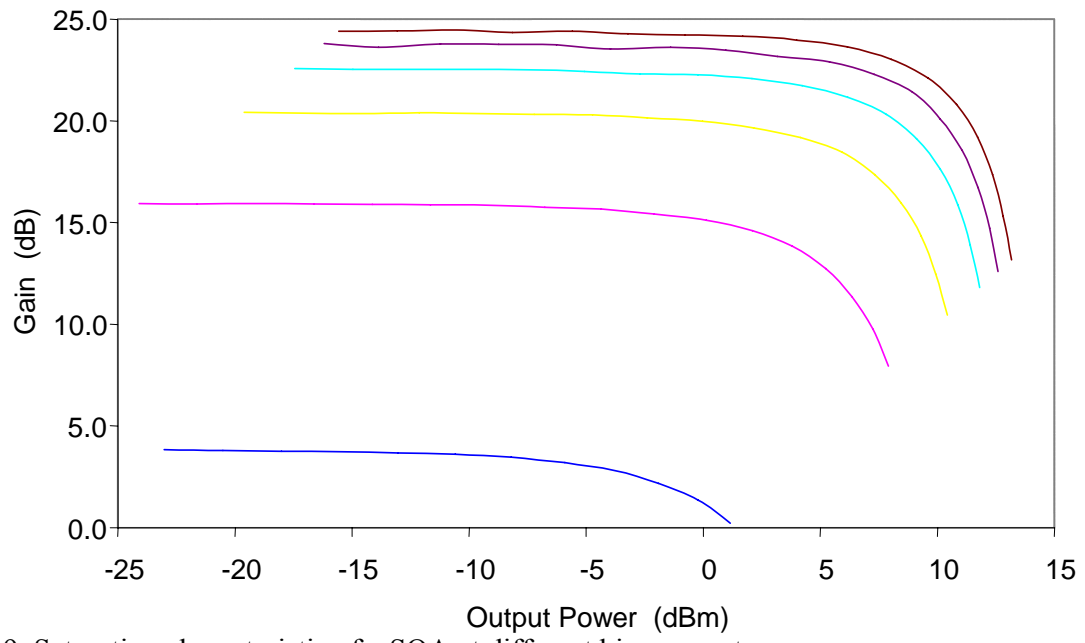

Fig. 9. Saturation characteristic of a SOA at different bias currents.

Clearly a gain-clamped SOA is not useful in this role since the gain is fixed during fabrication.

The realization of variable-gain, gain-clamped configuration is possible at the expense of a more complex architecture [65]. Use of a second (control) gain region that can be biased independently of the main (signal) gain block in effect creates a lasing cavity incorporating both primary and secondary amplifiers, the signal path branching off after passing through only the primary amplifier (Fig. 10).

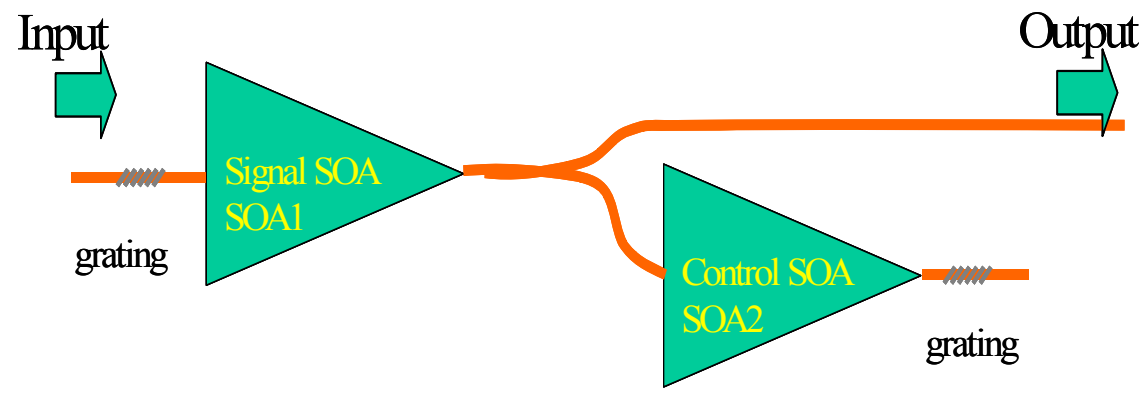

Fig. 10. Optical linear amplifier (OLA) geometry.

The tandem setup allows the effective reflectivity of the output side grating to be varied by altering the bias of the secondary, control SOA; and therefore the strength of the lasing mode can be influenced. This control mechanism for adjusting the lasing threshold then gives the module the ability to produce a primary amplification medium, which exhibits variable gain while at the same time preserving the good gain flatness and higher output saturation power values associated with a standard fixed gain-clamping regime. The output characteristics of such a device are shown in Fig. 11. We can see that the original saturated output is preserved even when the device is in attenuation. 


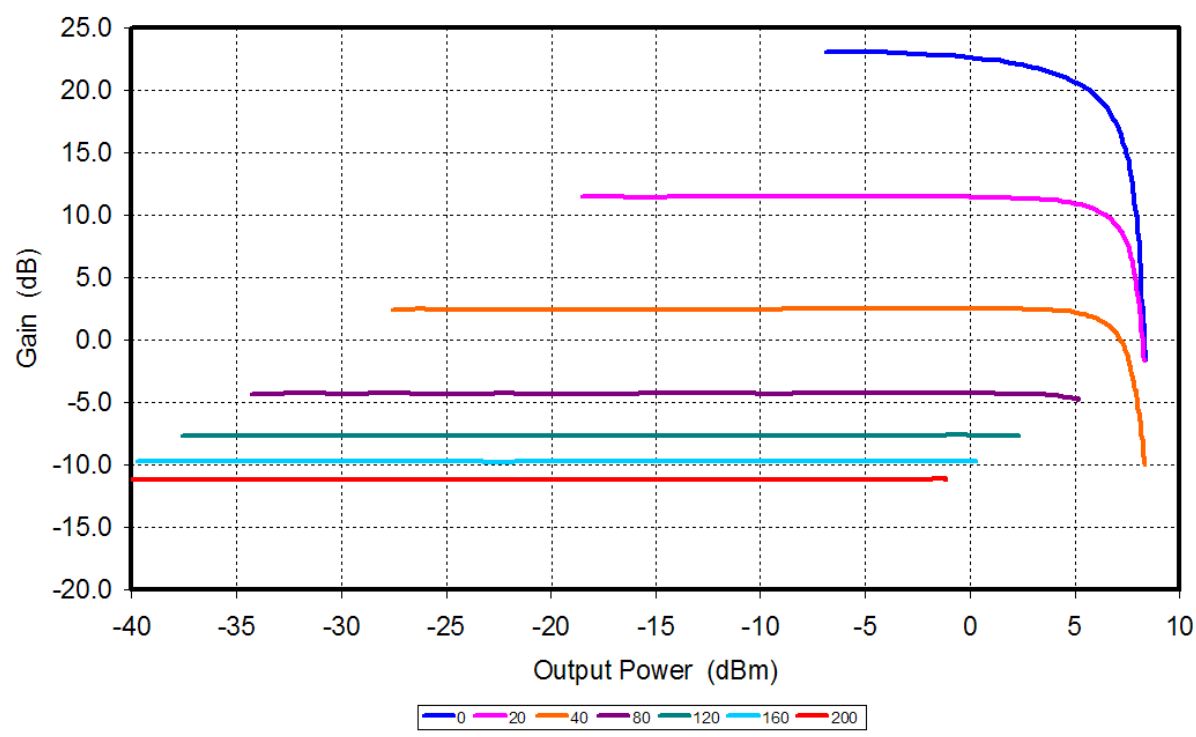

Fig. 11. Saturation characteristic for different control SOA bias currents.

\section{Conclusions}

The SOA is a versatile device with many advantageous characteristics that make it a leading choice for many of the functionalities required in the goal of realizing a highly dynamic future-proof optical layer. Whether as a single, discrete module acting as a linear amplifier, or as part of an integrated device in a highly functional platform such as a wavelength converter or regenerator, the SOA is a maturing technology with great application potential especially embedded in an integrated platform.

\section{Acknowledgments}

The authors thank Craig Michie for his contribution to this work, part of which was carried out at Kamelian Ltd.

\section{References and Links}

[1] M. J. O'Mahony, D. Simeonidou, D. K. Hunter, and A. Tzanakaki, "The application of optical packet switching in future communication networks," IEEE Commun. Mag. 39(3), 128-135 (2001).

[2] C. Guillemot, M. Renaud, P. Gambini, C. Janz, I. Andonovic, R. Bauknecht, B. Bostica, M. Burzio, F. Callegati, M. Casoni, D. Chiaroni, F. Clerot, S. L. Danielsen, F. Dorgeuille, A. Dupas, A. Franzen, P. B. Hansen, D. K. Hunter, A. Kloch, R. Krahenbuhl, B. Lavigne, A. Le Corre, C. Raffaelli, M. Schilling, J.-C. Simon, and L. Zucchelli, "Transparent optical packet switching: the European ACTS KEOPS project approach," J. Lightwave Technol. 16, 2117-2134 (1998).

[3] D. K. Hunter, M. H. M. Nizam, M. C. Chia, I. Andonovic, K. M. Guild, A. Tzanakaki, M. J. O’Mahony, L. D. Bainbridge, M. F. C. Stephens, R. V. Penty, and I. H. White, "WASPNET: a wavelength switched packet network," IEEE Commun. Mag. 37(3), 120-129 (1999).

[4] D. J. Blumenthal, B.-E. Olsson, G. Rossi, T. E. Dimmick, L. Rau, M. Masanovic, O. Lavrova, R. Doshi, O. Jerphagnon, J. E. Bowers, V. Kaman, L. A. Coldren, and J. Barton, "All-optical label swapping networks and technologies," J. Lightwave Technol. 18, 2058-2075 (2000).

[5] J.-Y. Emery, T. Ducellier, M. Bachmann, P. Doussiere, F. Pommereau, R. Ngo, F. Gaborit, L. Goldstein, G. Laube, and J. Barrau, "High performance $1.55 \mu \mathrm{m}$ polarisation insensitive semiconductor optical amplifier based on a low tensile strained bulk InGaAsP," Electron Lett. 33, 1083-1084 (1997).

[6] K. Morito, M. Ekawa, T. Watanabe, and Y. Kotaki, "High saturation output power $(+17 \mathrm{dBm}) 1550 \mathrm{~nm}$ polarisation insensitive semiconductor optical amplifier," European Conference on Optical Communication (ECOC 2000) (VDE, 2000), paper 1.3.2, pp. 39-41

[7] A. E. Kelly, C. Tombling, C. Michie, and I. Andonovic, "High performance semiconductor optical amplifiers," in Optical Fiber Communication Conference (OFC 2004), Vol. 95 of OSA Trends in Optics and Photonics Series (Optical Society of America, Washington, D.C., 2004), paper ThS1.

[8] J. R. Kim, J. S. Lee, S. Park, M. W. Park, J. S. Yu, S. D. Lee, A. G. Choo, T. I. Kim, and Y. H. Lee, "Spot size converter integrated polarization insensitive semiconductor optical amplifiers," IEEE Photon. Technol. Lett. 11, 967-969 (1999). 
[9] A. E. Kelly, I. F. Lealman, L. J. Rivers, S. D. Perrin, and M. Silver, "Low noise figure (7.2dB) and high gain(29dB) semiconductor optical amplifier with a single layer AR coating," Electron. Lett. 33, 536-538 (1997).

[10] B. Mersali, H. J. Bruckner, M. Feuillade, S. Sainson, A. Ougazzaden, and A. Carenco, "Theoretical and experimental studies of a spot size transformer with integrated waveguide for polarization insensitive optical amplifiers," J. Lightwave Technol. 13, 1865-1872 (1995).

[11] K. Dreyer, C. H. Joyner, J. L. Pleumeekers, C. A. Burrus, A. Dentai, B. I. Miller, S. Shunk, P. Sciortino, S. Chandrasekhar, L. Buhl, F. Storz, and M. Farwell, "High gain mode adapted semiconductor optical amplifier with $12.4 \mathrm{dBm}$ saturation output power at 1550nm," J. Lightwave Techol. 20, 718-721 (2002).

[12] A. Borghesani, N. Fensom, A. Scott, G. Crow, L. Johnston, J. King, L. Rivers, S. Cole, S. Perrin, D. Scrase, G. Bonfrate, A. Ellis, and I. Lealman, "High saturation output $(>16.5 \mathrm{dBm})$ and low noise figure $(<$ $6 \mathrm{~dB})$ semiconductor optical amplifier for $\mathrm{C}$ band operation," in Optical Fiber Communication Conference (OFC 2003), Vol. 86 of OSA Trends in Optics and Photonics Series (Optical Society of America, Washington, D.C., 2003), paper ThO1, pp. 534-536.

[13] T. Akiyama, M. Ekawa, M. Sugawara, H. Sudo, K. Kawaguchi, A. Kuramata, H. Ebe, K. Morito, H. Imai, and Y. Arakawa, "An ultrawide-band $(120 \mathrm{~nm})$ semiconductor optical amplifier having an extremely-high penalty-free outout power of $23 \mathrm{dBm}$ realized with quantum-dot active layers," in Optical Fiber Communication Conference (OFC 2004), Vol. 95 of OSA Trends in Optics and Photonics Series (Optical Society of America, Washington, D.C., 2004), postdeadline paper PDP12.

[14] T. Kakitsuka, Y. Shibata, M. Itoh, Y. Kadota, Y. Tohmori, and Y. Yoshikuni, "Influence of buried structure on polarization sensitivity in strained bulk semiconductor optical amplifiers," IEEE J. Quantum Electron. 38, 85-92.

[15] P. Doussiere, "Polarisation independent $1550 \mathrm{~nm}$ semiconductor optical amplifier packaged module with $29 \mathrm{~dB}$ fibre to fibre gain," in Proceedings of Conference on Optical Amplifiers and Their Applications (Optical Society of America, Washington, D.C., 1995).

[16] A. Ougazzaden, D. Sigogne, A. Mircea, E. V. K. Rao, A. Ramdane, and L. Silvestre, "Atmospheric pressure MOVPE growth of high performance polarization insensitive strain compensated MQW InGaAsP/InGaAs optical amplifier," Electron. Lett. 31, 1242-1244 (1995).

[17] L. F. Tiemeijer, P. J. A. Thijs, T. van Dongen, J. J. M. Binsma, and E. J. Jansen, "Polarisation resolved, complete characterization of $1310 \mathrm{~nm}$ fiber pigtailed multiple-quantum-well optical amplifiers," IEEE Photon. Technol. Lett. 14, 1524-1533 (1996).

[18] A. Godefroy, A. Le Corre, F. Clerot, S. Salaun, S. Loualiche, J. C. Simon, L. Henry, C. Vaudry, J. C. Keromnes, G. Joulie, and P. Lamouler, " $1.55 \mu \mathrm{m}$ polarization insensitive optical amplifier with strain balanced superlattice active layer," IEEE Photon. Technol. Lett. 7, 473-475 (1995).

[19] J. H. Marsh, "Quantum well intermixing," Semicond. Sci. Technol. 8, 1136-1150 (1993).

[20] J.-H. Ahn, K. R. Oh, J. S. Kim, S. W. Lee, H. M. Kim, K. E. Pyun, and H. M. Park, "Uniform and high coupling efficiency between InGaAsP-InP buried heterostructure optical amplifier and monolithically buttcoupled waveguide using reactive ion etching," IEEE Photon. Technol. Lett. 8, 200-202 (1996).

[21] I. Ogawa, F. Ebisawa, N. Yoshimoto, K. Takiguchi, F. Hanawa, T. Hashimoto, A. Sugita, M. Yanagisawa, Y. Inoue, Y. Yamada, Y. Tohmori, T. Ito, K. Magari, Y. Kawaguchi, A. Himeno, and K. Kato, "Lossless hybrid integrated 8 channel wavelength selector module," in Optical Fiber Communication Conference (OFC 1998), OSA Technical Digest Series (Optical Society of America, Washington, D.C., 1998), paper PD4.

[22] F. Ebisawa, I. Ogawa, Y. Akahori, K. Takiguchi, Y. Tamura, T. Hashimoto, A. Sugita, Y. Yamada, Y. Suzaki, N. Yoshimoto, Y. Tohmori, S. Mino, T. Ito, K. Magari, Y. Kawaguchi, H. Himeno, and K. Kato, "High speed 32 channel optical wavelength selector using PLC hybrid integration," in Optical Fiber Communication Conference (OFC 1999), OSA Technical Digest Series (Optical Society of America, Washington, D.C., 1999), paper ThB1, pp. 18-20.

[23] T. Kato, J. Sasaki, T. Shimoda, H. Hatakeyama, T. Tamanuki, M. Yamaguchi, M. Kitamura, and M. Itoh, "10Gb/s photonic cell switching with hybrid 4x4 optical matrix switch module on planar waveguide platform," in Optical Fiber Communication Conference (OFC 1998), OSA Technical Digest Series (Optical Society of America, Washington, D.C., 1998), paper PD3.

[24] R. Sato, Y. Suzuki, N. Yoshimoto, I. Ogawa, T. Hashimoto, T. Ito, A. Sugita, Y. Tohimori, and H. Toba, "A $1.55 \mu \mathrm{m}$ hybrid integrated wavelength-converter module using spot-size converter integrated semiconductor optical amplifiers on a planar-lightwave-circuit platform," IEICE Trans. Commun. E82-B, 753-759 (1999).

[25] R. Sato, "Wide temperature operation of a hybridly integrated wavelength converter module," in Proceedings of Conference on Optical Amplifiers and Their Applications (Optical Society of America, Washington, D.C., 1998).

[26] G. Maxwell, R. J. Manning, M. Nield, M. Harlow, C. Ford, M. Clements, S. Lucas, P. Townley, R. McDougall, S. Oliver, R. Cecil, L. Johnston, A. Poustie, R. Webb, I. Lealman, L. Rivers, J. King, S. Perrin, R. Moore, I. Reid, and D. Scrase, "Very low coupling loss, hybrid-integrated all-optical regenerator with passive assembly," in European Conference on Optical Communication (ECOC 2002) (IEE, 2002), postdeadline paper PD3.5. 
[27] D. D. Marcenac, A. E. Kelly, D. Nesset, and D. A. O. Davies, "Bandwidth enhancement of wavelength conversion by semiconductor optical amplifier cascade," Electron. Lett. 31, 1442- 1443 (1995).

[28] A. Mecozzi, "Analytical theory of four wave mixing in semiconductor optical amplifiers," Opt. Lett. 19, 892-894.

[29] R. J. Manning, A. E. Kelly, A. J. Poustie, and K. J. Blow, "Wavelength dependence of switching contrast ratio of a semiconductor optical amplifier based nonlinear loop mirror," Electron. Lett. 34, 916-918 (1998).

[30] A. E. Kelly, D. D. Marcenac, and D. Nesset, "40Gbit/s wavelength conversion over 24.6nm using FWM in a semiconductor optical amplifier with an optimized MQW active region," Electron. Lett. 33, 2123-2124 (1997).

[31] C -Y. Jin, Y.-Z. Huang, L.-J. Yu and S.-L. Deng, "Detailed model and investigation of gain saturation and carrier spatial hole burning for a semiconductor optical amplifier with gain clamping by a vertical laser field," J. Quantum Electron. 40, 513-518 (2004).

[32] G. Soulage, "8 channels, $10 \mathrm{Gbit} / \mathrm{s}$ operation of a clamped-gain semiconductor optical amplifier," in Proceedings of the Conference on Lasers and Electro-Optics (IEEE, 1996), paper CMA2, 05/96.

[33] M. S. Nomura, F. Salleras, M. A. Dupertuis, L. Kappei, D. Marti, B. Deveaud, J.-Y. Emery, A. Crottini, B. Dagens, T. Shimura, and K. Kuroda, "Density clamping and longitudinal spatial hole burning in a gain-clamped semiconductor optical amplifier," Appl. Phys. Lett. 81, (2002).

[34] K. Morito, M. Ekawa, T. Watanabe and Y. Kotaki, "High-output-power polarization-insensitive semiconductor optical amplifier," J. Lightwave Technol. 21, (2003).

[35] J. Gri , M. Duelk, J. E. Simsarian, A. Bhardwaj, P. Bernasconi, O. Laznicka, and M. Zirngibl, "Optical switch fabrics for ultra-high-capacity IP routers," J. Lightwave Technol. 21, 176-181 (2003).

[36] P. Gambini, M. Renaud, C. Guillemot, F. Callegati, I. Andonovic, B. Bostica, D. Chiaroni, G. Corazza, S. L. Danielsen, P. Gravey, P. B. Hansen, M. Henry, C. Janz, A. Kloch, R. Krathenbuhl, C. Raffaelli, M. Schilling, A. Talneau, and L. Zucchelli, "Transparent optical packet switching: network architecture and demonstrators in the KEOPS project” J. Sel. Areas Commun. 16, 1245-1259 (1998).

[37] M. J. O’Mahony, K. M. Guild, D. K. Hunter, I. Andonovic, I. H. White, and R. V. Penty, "All-optical packet switched network (WASPNET) — concept and realisation," Opt. Netw. Mag. 2, 46-53 (2001).

[38] T. Ito, N. Yoshimoto, K. Magari, and H. Sugiura, "Wide-band polarization-independent tensile strained InGaAs MQW-SOA gate," IEEE Photon. Technol. Lett. 10, 657-659 (1998).

[39] K. Wakao, H. Soda, and Y. Kotaki, "Semiconductor optical active devices for photonic networks,"Fujitsu Sci. Tech. J. 35, 100-106 (1999).

[40] N. Sahri, D. Prieto, S. Silvestre, D. Keller, F. Pommerau, M. Renaud, O. Rofidal, A. Dupas, F. Dorgeuille, and D. Chiaroni., "A highly integrated 32-SOA gates optoelectronic module suitable for IP multi-Terabit optical packet routers," in Optical Fiber Communication Conference (OFC 2002), Vol. 70 of OSA Trends in Optics and Photonics Series (Optical Society of America, Washington, D.C., 2002), Vol.4, pp. PD32-1-PD32-3.

[41] R. Ramamurthy and B. Mukherjee, "Fixed-alternate routing and wavelength conversion in wavelengthrouted optical networks," IEEE/ACM Trans. Netw. 10, 351-367 (2002).

[42] T. Durhuus, B. Mikkelsen, C. Joergensen, S. L. Danielsen, and K. E. Stubkjaer, "All-optical wavelength conversion by semiconductor optical amplifiers," J. Lightwave Technol. 14, 942- 954 (1996).

[43] C. Guillemot, P. Gambini, M. Renaud, F. Callegati, I. Andonovic, B. Bostica, D. Chiaroni, G. Corazza, S. L. Danielsen, P. Gravey, P. B. Hansen, M. Henry, C. Janz, A. Kloch, R. Krahenbuhl, C. Raffaelli, M. Schilling, A. Talneau, and L. Zucchelli, "Transparent optical packet switching: network architecture and demonstrators in the KEOPS project," IEEE J. Sel. Areas Commun. 16, 1245-1259 (1998).

[44] I. Armstrong, I. Andonovic, J. Bebbington, C. Michie, C. Tombling, S. Fasham, A. E. Kelly, Y. J. Chai, R. V. Penty, and I. H. White, "Hybridisation platform demonstrating all optical wavelength conversion at 10 and 20Gbit/s," in Optical Fiber Communication Conference (OFC 2004), Vol. 95 of OSA Trends in Optics and Photonics Series (Optical Society of America, Washington, D.C., 2004), paper ThS3.

[45] J. P. R. Lacey, M. A. Summerfield, and S. J. Madden, "Tunability of polarization-insensitive wavelength converters based on four-wave mixing in semiconductor optical amplifiers," J. Lightwave Technol. 16, 24192427 (1998).

[46] K. Uchiyama, S. Kawanishi, and M. Saruwatari, "100-Gb/s multiple-channel output all-optical OTDM demultiplexing using multichannel four-wave mixing in a semiconductor optical amplifier," Photon. Technol. Lett., 10, 890-892 (1998).

[47] D. Nesset, M. C. Tatham, and D. Cotter, " All-optical AND gate operating on $10 \mathrm{Gbit} / \mathrm{s}$ signals at the same wavelength using four-wave mixing in a semiconductor laser amplifier," Electron. Lett. 31, 896-897 (1995).

[48] A. E. Kelly, I. D. Phillips, R. J. Manning, A. D. Ellis, D. Nesset, D. G. Moodie and R. Kashyap, "80Gbit/s all optical regenerative wavelength conversion using a semiconductor optical amplifier based interferometer," Electronics Letters 35, 17, 1477-1478 (Aug 1999)

[49] A. E. Kelly, A. D. Ellis, D. Nesset, R. Kashyap, and D. G. Moodie, "100 Gbit/s wavelength conversion using FWM in an MQW semiconductor optical amplifier," Electron. Lett. 34, 1955-1956 (1998).

[50] R. J. Manning, I. D. Phillips, A. D. Ellis, A. E. Kelly, A. J. Poustie, and K. J. Blow, "10 Gbit/s all-optical regenerative memory using a single SOA based logic gate," Electron. Lett. 35, 158-159 (1999). 
[51] D. Cotter, R. J. Manning, K. J. Blow, A. D. Ellis, A. E. Kelly, D. Nesset, I. D. Phillips, A. J. Poustie, and D.C. Rogers, "Non-linear optics for high speed digital information processing," Science 286, 1523-1528 (1999)

[52] D. Tsiokos, E. Kehayas, K. Vyrsokinos, T. Houbavlis, L. Stampoulidis, G. T. Kanellos, N. Pleros, G. Guekos and H. Avramopoulos, "10-Gb/s All-optical half-adder with interferometric SOA gates," IEE Photon. Technol. Lett. 16, 284-286 (2004).

[53] A. J. Poustie, K. J. Blow, A.E. Kelly and R. J. Manning, "All-optical binary half adder," Opt. Commun. 156, 22-26 (1998).

[54] A. J. Poustie, K. J. Blow, A. E. Kelly, and R. J. Manning, "All-optical full adderwith bit differential delay," Opt. Commun. 168, 89-93 (1999).

[55] C. Bintjas, N. Pleros, K. Yiannopoulos, G. Theophilopoulos, M. Kalyvas, H. Avramopoulos, and G. Guekos, "All-optical packet address and payload separation," IEE Photon. Techol. Lett. 14, 1728-1730 (2002).

[56] N. Calabretta, Y. Lui, F. M. Huijskens,M. T. Hill, H. deWaardt, G. D. Khoe, and H. J. S. Dorren, "Optical signal processing based on self-induced polarization rotation in semiconductor optical amplifier," J. Lightwave Technol. 22, 372-381 (2004).

[57] S. A. Hamilton, B. S. Robinson, T. E. Murphy, S. J. Savage, and E. P. Ippen, "100 Gb/s optical timedivision multiplexed networks," J. Lightwave Technol. 20, 2086-2100 (2002).

[58] H. J. S. Dorren, Y. Lui, N. Calabretta, A. Srivatsa, F. M. Huijskens, H. de Waardt, and G. D. Khoe, "Optical packet switching and buffering by using all-optical signal processing methods," J. Lightwave Technol. 21, 2-12 (2003).

[59] A. J. Poustie, K. J. Blow, A. E. Kelly, and R. J. Manning, "All-optical parity checker with bit differential delay," Opt. Commun. 162, 37-43(1999).

[60] A. J. Poustie, K. J. Blow, R. J. Manning, and A. E. Kelly, "All-optical pseudo-random number generator," Opt. Commun. 159, 208-214 (1998)

[61] A. E. Kelly, R. J. Manning, A. J. Poustie and K. J. Blow, "All-optical clock division at 10GHz and 20GHz in a semiconductor amplifier based non-linear loop mirror," Electron. Lett. 34, 1337-1339 (1998).

[62] R. J. Manning, I. D. Phillips, A. D. Ellis, A. E. Kelly, A. J. Poustie, and K. J. Blow, "All-optical clock divisionat $40 \mathrm{GHz}$ using a semiconductor amplifier based nonlinear interferometer," Electron. Lett. 35, 827-829 (1999).

[63] R. J. Manning, I. D. Phillips, A. D. Ellis, A. E. Kelly, A. J. Poustie, and K. J. Blow, "10 Gbit/s all-optical regenerative memory using a single SOA based logic gate," Electron. Lett. 35, 158-159 (1999).

[64] D. Chiaroni, N. Le Sauze, T. Zami and J.-Y. Emery, "Semiconductor Optical Amplifiers : a key technology to control the packet power variation," in 27th European Conference on Optical Communication (ECOC 01) (IEE, 2001), Vol. 3, pp. 314-315.

[65] W. C. Michie, A. E. Kelly, A. Tomlinson, and I. Andonovic, “ in Semiconductor Lasers and Optical Amplifiers for Lightwave Communication Systems, R. P. Mirin and C. S. Menoni, eds., Proc. SPIE 4871, 1-8 (2002). 